\title{
Trauma center accessibility for road traffic injuries in Hanoi, Vietnam
}

\author{
Takashi Nagata $^{1 *}$, Ayako Takamori ${ }^{2}$, Yoshinari Kimura ${ }^{3}$, Akio Kimura ${ }^{4}$, Makoto Hashizume ${ }^{1}$ and Shinji Nakahara ${ }^{5}$
}

\begin{abstract}
Background: Rapid economic growth in Vietnam over the last decade has led to an increased frequency of road traffic injury (RTI), which now represents one of the leading causes of death in the nation. Various efforts toward injury prevention have not produced a significant decline in the incidence of RTIs. Our study sought to describe the geographic distribution of RTIs in Hanoi, Vietnam and to evaluate the accessibility of trauma centers to those injured in the city.
\end{abstract}

Methods: We performed a cross-sectional study using Hanoi city police reports from 2006 to describe the epidemiology of RTIs occurring in Hanoi city. Additionally, we identified geographic patterns and determined the direct distance from injury sites to trauma centers by applying geographical information system (GIS) software. Factors associated with the accessibility of trauma centers were evaluated by multivariate regression analysis.

Results: We mapped 1,271 RTIs in Hanoi city. About 40\% of RTIs occurred among people 20-29 years of age. Additionally, $63 \%$ of RTls were motorcycle-associated incidents. Two peak times of injury occurrence were observed: $12 \mathrm{am}-4$ pm and 8 pm-0 am. "Hot spots" of road traffic injuries/fatalities were identified in the city area and on main highways using Kernel density estimation. Interestingly, RTIs occurring along the two north-south main roads were not within easy access of trauma centers. Further, fatal cases, gender and injury mechanism were significantly associated with the distance between injury location and trauma centers.

Conclusions: Geographical patterns of RTIs in Hanoi city differed by gender, time, and injury mechanism; such information may be useful for injury prevention. Specifically, RTIs occurring along the two north-south main roads have lower accessibility to trauma centers, thus an emergency medical service system should be established.

\section{Introduction}

In Vietnam, road traffic injuries (RTIs) are becoming a major public health issue [1]. These injuries occur more frequently due to rapid economic growth and motorization in recent years; indeed, the number of road traffic fatalities nationally rose from 4,907 in 1994 to 11,534 in 2005. RTI are the leading cause of death in the $15-59$ years age group, while RTI is the second in men and the fifth in women most frequent causes of death among the total population [2]. Economic loss also results from RTIs, and is currently estimated at about 855 million US dollars (or 2.45\% of Gross Domestic Product) per year [1,3].

Policy changes are needed to mitigate this major public health issue. For example, injury prevention programs

\footnotetext{
* Correspondence: nagata.takashi@gmail.com

'Kyushu University Hospital, Department of Emergency and Critical Care Center, Fukuoka, Japan Full list of author information is available at the end of the article
}

are effective in reducing RTIs: the helmet law enacted by the Vietnamese government in December 2007 increased the incidence of helmet use among motorcyclists to around $85 \%$ and substantially decreased motorcyclerelated head injuries $(-16 \%)$ and fatalities $(-18 \%)[4,5]$. Additional prevention programs may result in declines in RTIs. Alternatively, an emergency medical service (EMS) can be effective at reducing losses associated with RTI, by streamlining the chain of survival [6]. While Vietnam has some EMSs, they are not structured, insurance issues are often undetermined, and the real performance of the EMS remains unclear. Effective EMS systems depend upon the prompt transportation of injured people from the scene to the trauma center. Transportation time is directly influenced by the location of the RTI occurrence, of the ambulance dispatch center, and of the trauma center. Therefore, examining the geographical distribution of RTI occurrence and the distance between injury scenes
C Biomed Central 
and trauma centers can provide useful information in planning EMS systems, particularly new ambulance dispatch centers or trauma centers.

A useful tool for investigating such geographical factors is the geographical information system (GIS). GIS is widely applied to various areas of scientific research, including RTIs $[7,8]$, and offers two advantages: visual results and subsequent application of spatial analysis. For our study, GIS was used to determine accessibility to trauma centers from injury scenes. Specifically, we aimed to describe the geographical distribution of RTIs and evaluate the accessibility to trauma centers for those injured in Hanoi, Vietnam.

\section{Methods}

We performed a cross-sectional study using data from the Hanoi city police agency. Hanoi is the capital of Vietnam, with an estimated population of 6,232,940 people in 2008. The city has experienced rapid economic growth since the 1990s, with a corresponding increase in motor vehicle use. In 2004, with the support of the Japanese government, the Hanoi city police and city traffic agency established a database for RTI. Following a road traffic incident in Hanoi-for example, a motorcycle versus motorcycle collision-if police were contacted, the incident was investigated and registered in the database. Major injury or fatality cases were often reported to the police. Road traffic fatality was defined as a death occurring at the scene of a road traffic incident and road traffic injury was defined as severe cases caused by road traffic incidents in this database. In 2006, database entries were not subjected to specific inclusion criteria: however, severe and fatal cases were entered in this database.

Anonymous, registered cases of road traffic injuriesincluding fatalities-occurring in Hanoi between January $1^{\text {st }}, 2006$ and December $31^{\text {st }}, 2006$ were included in our study. Data retrieved for each case included age, gender, time of injury, injury mechanism (motorcycle versus motorcycle, motorcycle versus car, motorcycle versus bicycle, motorcycle versus pedestrian, motorcycle versus train, car versus car, car versus bicycle, car versus pedestrian, car versus train, etc), and injury location.

We evaluated the basic characteristics for RTIs, and then mapped the cases to Hanoi using GIS software ArcMap 9.2 (ESRI Co Ltd) and address matching. Kernel density estimation, a non-parametric approach to estimating a probability density function for random variables, was applied to determine the incidence of road traffic fatalities/injuries. In GIS, Kernel density estimation is used to calculate the magnitude per unit area using a Kernel function to fit a smoothly tapered surface to each point. In this analysis, the radius, or band-width, was set to 1,000 meters. Viet Duc Hospital, Bach Mai Hospital, and Saint Paul Hospital were active trauma centers in
Hanoi in 2006. These hospitals are located near one another at the center of Hanoi. The direct distance between site of road traffic injury and each of these three hospitals was measured to determine accessibility of RTIs to trauma centers.

Multivariate linear regression analysis was used to investigate factors associated with the distance between injury location and trauma centers. The outcome variable of the regression model was the direct distance $(\mathrm{km})$ between the site of road traffic injury and Viet Duc Hospital, which has the largest trauma center in Hanoi, Vietnam. Road traffic fatality or injury, age groups (20-29 years of age or other), gender (male or female), time (morning: $0 \mathrm{am}-11 \mathrm{am}$, afternoon: 11 am- 6 pm, night: 6 pm-0 am), day (weekday: Monday-Friday, weekend: Saturday and Sunday) and injury mechanism (motorcycle versus motorcycle, motorcycle versus car, bicycle-associated, pedestrian-associated and others), were used as explanatory variables. SAS 9.2 was used in data analysis. $p$-values less than 0.05 were

\section{Table 1 Basic characteristics of road traffic injuries in} Hanoi, 2006

\begin{tabular}{|c|c|c|}
\hline Variable & $\mathbf{N}$ & Mean (SD) or Percentage \\
\hline Distance (km) & 1271 & $6.781(5.316)$ \\
\hline \multicolumn{3}{|l|}{ Fatality or Injury } \\
\hline Fatality & 424 & $41 \%$ \\
\hline Injury & 610 & $59 \%$ \\
\hline Total & 1034 & $100 \%$ \\
\hline \multicolumn{3}{|l|}{ Gender } \\
\hline Male & 818 & $79 \%$ \\
\hline Female & 216 & $21 \%$ \\
\hline Total & 1034 & $100 \%$ \\
\hline \multicolumn{3}{|l|}{ Age groups } \\
\hline $20-29$ years & 423 & $46 \%$ \\
\hline Other & 504 & $54 \%$ \\
\hline Total & 927 & $100 \%$ \\
\hline \multicolumn{3}{|l|}{ Time } \\
\hline Morning (0 am - 11 am) & 382 & $30 \%$ \\
\hline Afternoon (11 am - 6 pm) & 383 & $30 \%$ \\
\hline Night (6 pm - 0 am) & 496 & $40 \%$ \\
\hline Total & 1261 & $100 \%$ \\
\hline \multicolumn{3}{|l|}{ Day } \\
\hline Weekday & 410 & $32 \%$ \\
\hline Weekend & 861 & $68 \%$ \\
\hline Total & 1271 & $100 \%$ \\
\hline \multicolumn{3}{|l|}{ Injury Mechanism } \\
\hline Motorcycle vs. motorcycle & 347 & $28 \%$ \\
\hline Motorcycle vs. car & 427 & $35 \%$ \\
\hline Pedestrian-associated & 157 & $13 \%$ \\
\hline Bicycle-associated & 100 & $8 \%$ \\
\hline Others & 193 & $16 \%$ \\
\hline Total & 1224 & $100 \%$ \\
\hline
\end{tabular}

SD: Standard Deviation 
accepted as statistically significant. The study was approved by the Institutional Review Board at Kurume University, Japan.

\section{Results}

During the study period, 1,490 road traffic injuries were registered. Among these, data for injury location/site of road traffic incident were documented in 1,271. Thus, 209 cases either lacked data for injury location or the address could not be located on the map of Hanoi.

Demographic characteristics of RTIs in Hanoi in 2006 are shown in Table 1. Cases tended to be 20-29 years of age and male. Additionally, more than $63 \%$ of RTIs/fatalities were motorcycle versus motorcycle/car.

Interestingly, RTIs were more likely to occur during two peak times of day: between 12 am and $4 \mathrm{pm}$ and between $8 \mathrm{pm}$ and 0 am (Figure 1). Figure 2 shows the geographical distribution of RTIs (red dot) and hospital/health care centers (blue dot) in Hanoi, while Figure 3 shows the Kernel density of RTIs (band-width of 1,000 meters). RTIs were clustered in "hot zones" in the central city area and along the two north-south main roads (highways, Routes 3 and 8). The hospitals were also clustered in the center of the city, including three major trauma centers (Viet Duc Hospital, Bach Mai Hospital, and Saint Paul Hospital). The median direct distances between injury sites and the three trauma centers were $5.65(3.19$ - 8.64) $\mathrm{km}$ for Viet Duc Hospital, 5.31 (2.89 - 8.54) km for Bach Mai Hospital, and 5.11 (3.11 - 8.72) km for Saint Paul Hospital.

The estimations of Pearson's correlation regarding mutual relationships of the explanatory variables were less than 0.125 , and the issue of multi-colinearity could be omitted.

The result of a multivariate linear regression analysis indicated that the direct distance from the injury sites to Viet Duc Hospital were significantly associated with fatality, gender and mechanism of injury (Table 2). Compared with RTI, road traffic fatalities occurred $1.538 \mathrm{~km}$ farther from Viet Duc hospital significantly ( $p$ value $<0.0001)$. Compared with females, male RTIs occurred $1.082 \mathrm{~km}$ farther from Viet Duc hospital significantly $(p$-value $=0.019)$. Finally, compared with motorcycle versus motorcycle incidents, motorcycle versus car incidents occurred $2.715 \mathrm{~km}$ farther from Viet Duc Hospital significantly ( $p$-value $<0.001)$. Similar results were observed for Bach Mai and Saint Paul hospitals (not shown).

\section{Discussion}

Our study determined the geographical distribution of RTIs in Hanoi in 2006. RTIs were clustered in the center of the city and along the two major north-south roads

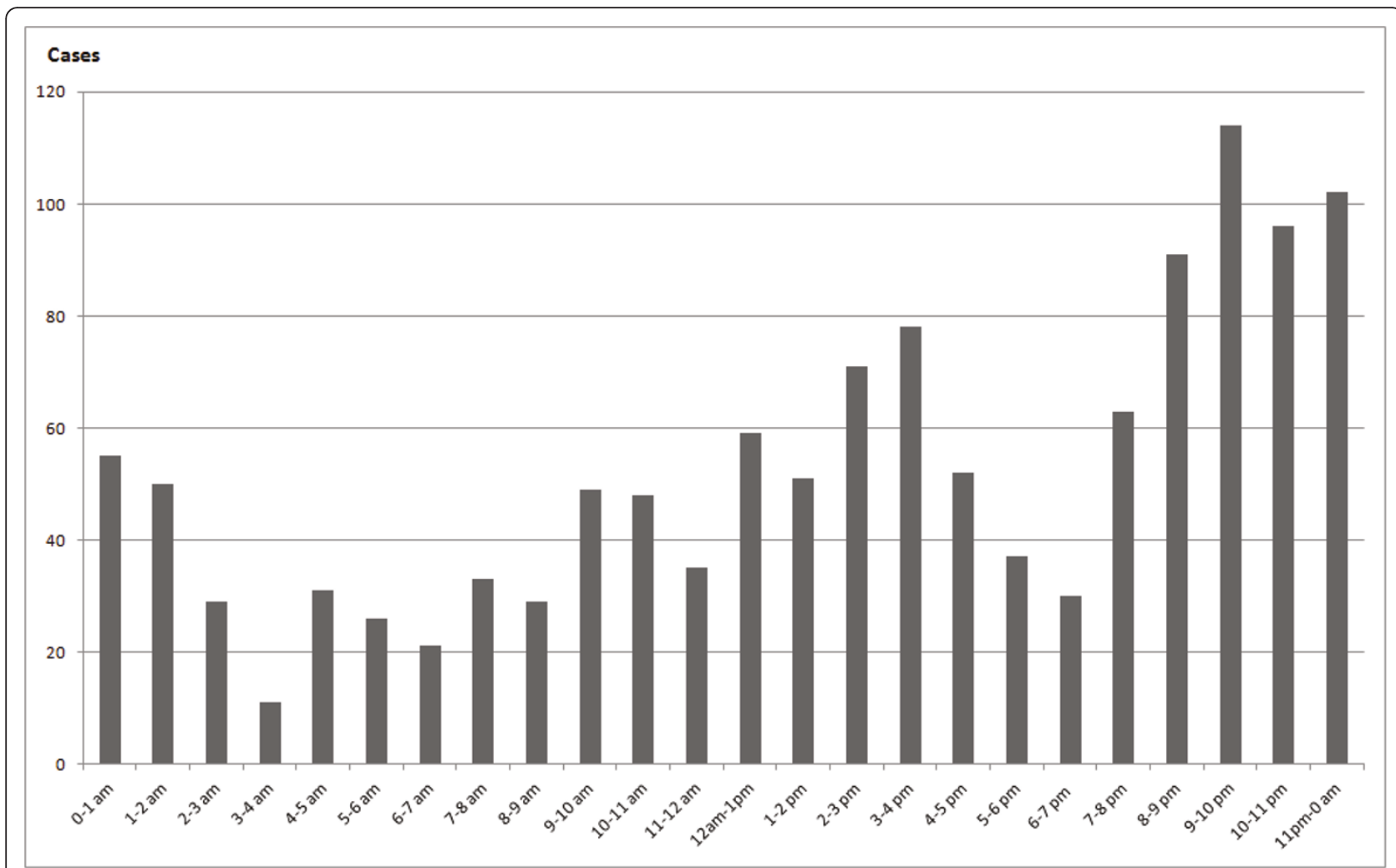

Figure 1 Time distribution of road traffic injuries occurring in Hanoi, Vietnam. 


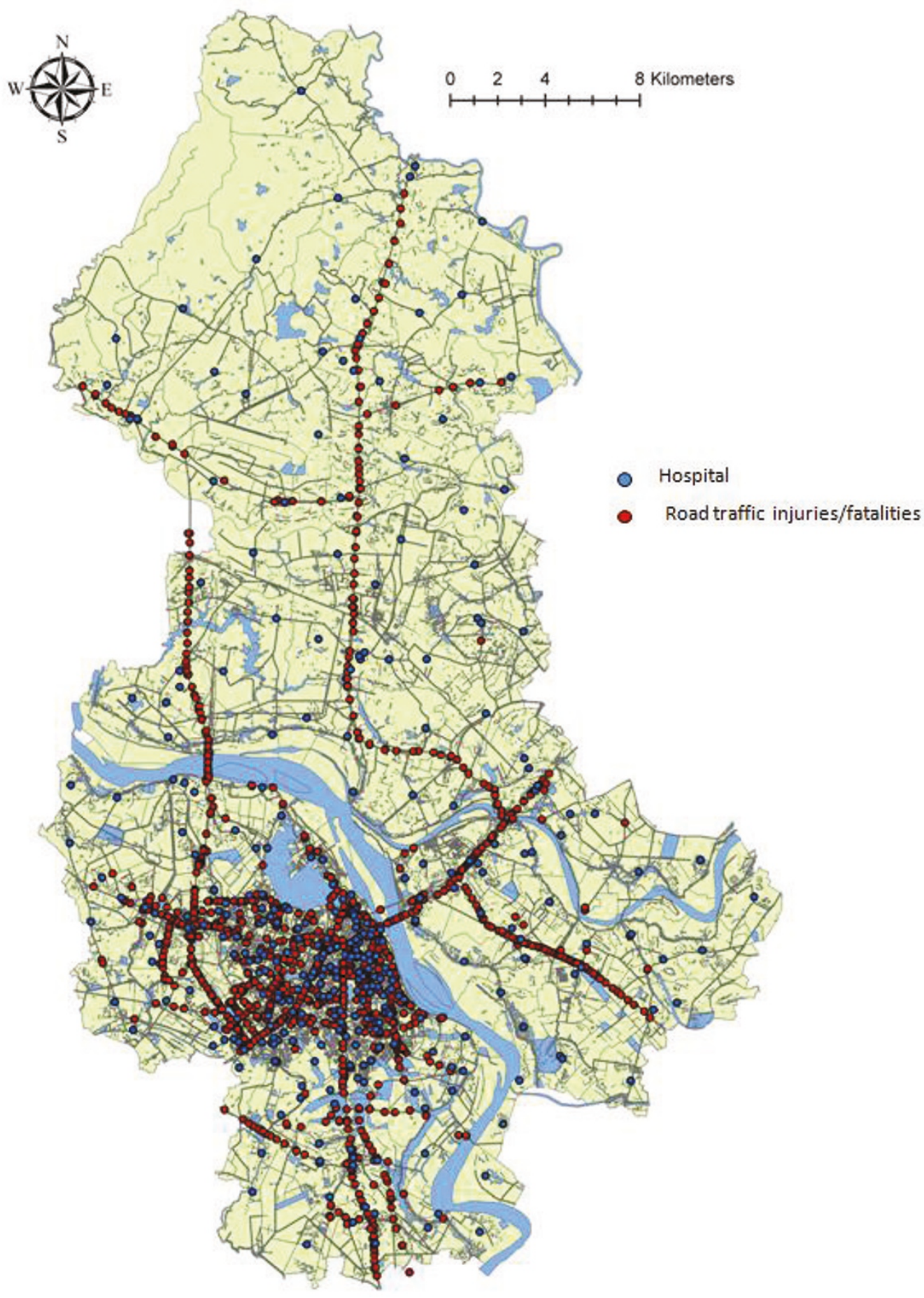

Figure 2 GIS-based map of road traffic injuries (red dots) and hospitals (blue dots) in Hanoi, Vietnam

(Routes 3 and 8). As shown in Table 2, the multiple regression analysis showed that the direct distance from the injury sites to the major trauma center (Viet Duc Hospital) was statistically longer with road traffic fatality, male or motorcycle vs. car incidents. This finding likely reflects a predominance of cars on major roads outside the city area, such as Routes 3 and 8, high risk-taking behavior in males (high speed and alcohol driving), and 


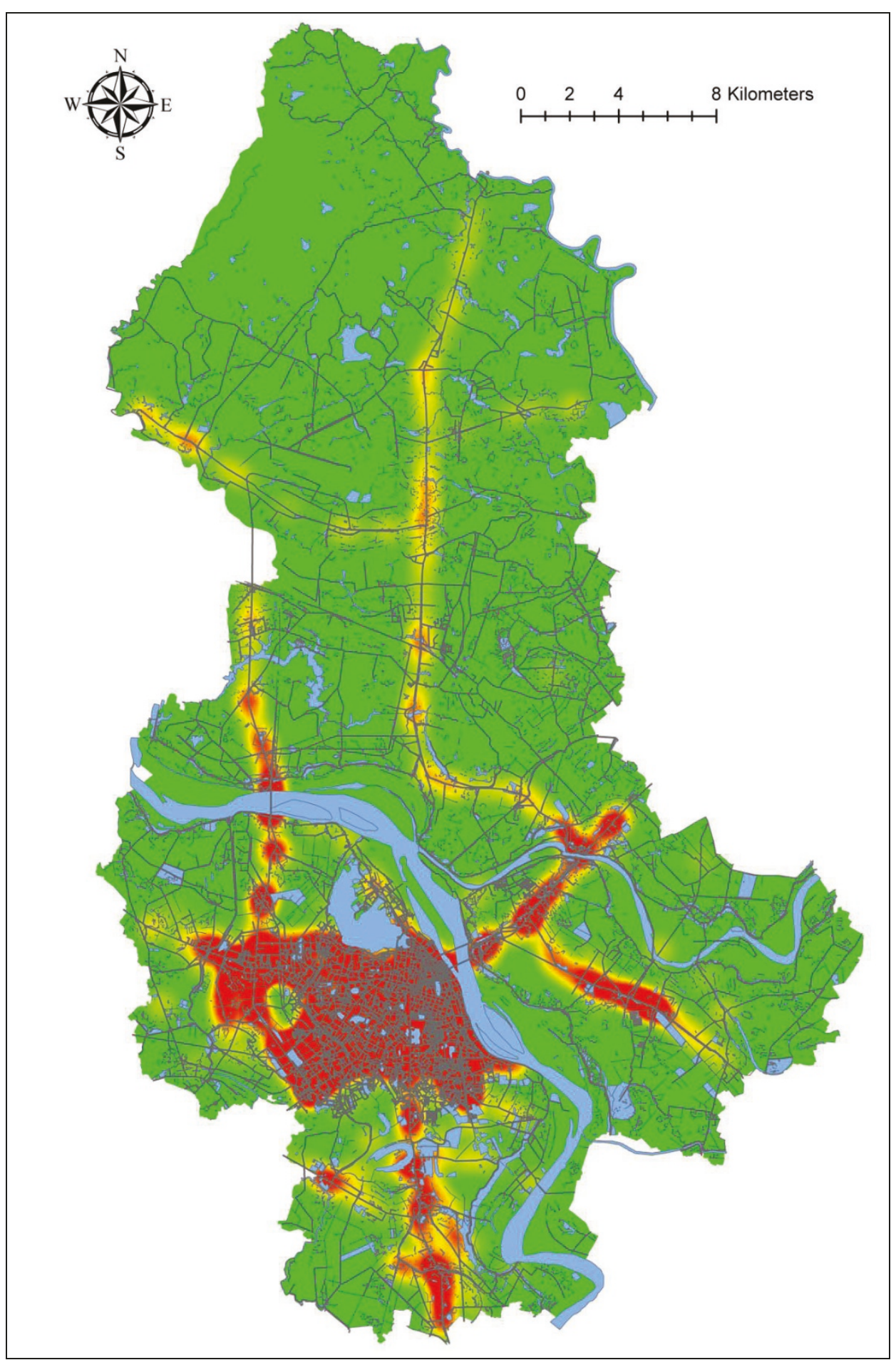

Figure 3 Kernel density estimation of the occurrence of road traffic injuries in Hanoi, Vietnam.

lack of a prehospital care system [9]. Also, male motorcyclists tend to drive outside downtown while female motorcyclists drive inside downtown.

In Vietnam, RTI is one of the leading causes of morbidity and mortality. Correspondingly, great effort has been made to prevent these injuries, with changes in traffic regulations and helmet law endorsement, and to better treat them through improved trauma center care and EMS [4,5,9-12]. We recommend additional measures to reduce the effects of road traffic injuries in Hanoi city. EMS 
Table 2 The adjusted effects of fatalities, gender, age group, time, day, and injury mechanism on trauma center access (Viet Duc Hospital) for road traffic injury by a multiple regression model

\begin{tabular}{|c|c|c|c|}
\hline Variable & Coefficient & SE & $p$-value \\
\hline \multicolumn{4}{|l|}{ Fatality or Injury $^{1}$} \\
\hline Fatality & 1.538 & 0.378 & $<0.0001$ \\
\hline \multicolumn{4}{|l|}{ Gender $^{2}$} \\
\hline Male & 1.082 & 0.458 & 0.019 \\
\hline \multicolumn{4}{|l|}{ Age groups ${ }^{3}$} \\
\hline $20-29$ years & 0.394 & 0.373 & 0.292 \\
\hline \multicolumn{4}{|l|}{ Time $^{4}$} \\
\hline Morning (0 am - 11 am) & -0.618 & 0.451 & 0.171 \\
\hline Afternoon (11 am - 6 pm) & -0.024 & 0.445 & 0.957 \\
\hline \multicolumn{4}{|l|}{ Day $^{5}$} \\
\hline Weekday & 0.560 & 0.395 & 0.156 \\
\hline \multicolumn{4}{|l|}{ Injury Mechanism ${ }^{6}$} \\
\hline Motorcycle vs. car & 2.715 & 0.470 & $<0.0001$ \\
\hline Bicycle-associated & 1.311 & 0.761 & 0.085 \\
\hline Pedestrian-associated & 0.594 & 0.638 & 0.352 \\
\hline Others & 0.722 & 0.571 & 0.207 \\
\hline
\end{tabular}

${ }^{1}$ Compared with injury (reference category)

${ }^{2}$ Compared with female (reference category)

${ }^{3}$ Compared with other ages (reference category)

${ }^{4}$ Compared with night (reference category)

${ }^{5}$ Compared with weekend (reference category)

${ }^{6}$ Compared with motorcycle vs. motorcycle (reference category)

dispatch centers along Routes 3 and 8 or pre-hospital transport by commercial vehicles would improve accessibility to care following a road traffic incident in these "hot zones" $[13,14]$. Indeed, new trauma centers along Routes 3 and 8 would be more effective at reducing RTIs; however, limited finances and infrastructure conditions may prohibit such a measure.

There are several limitations to this study. First, the data used in this study were not linked with hospital records, and clinical outcomes could not be confirmed. Second, only severe/fatal road traffic incidents were included in the registry, thus under-reporting of incidents was possible [15]. However, the occurrence of a number of RTIs far from trauma centers was not influenced by potential under-reporting. While data collection by the Hanoi city police agency was supported by international cooperation from Japan at an early stage of the project, data quality might be insufficient [16]. Third, GIS data were not fully available in Hanoi in 2006, and further geo-statistical analysis could not be performed in this study. Fourth, to accurately evaluate accessibility of trauma centers, travel time and the actual distance traveled by a vehicle-rather than shortest distance on a map-should be assessed. This approach would be helpful in determining whether the EMS system should be "scoop and run" or "stay and play" [17]. However, an important limitation of our study was that we did not have access to data regarding travel time or actual distance traveled. Therefore our analysis did not include these variables.

GIS is widely used in emergency medicine research [18-20]. In a retrospective study, Peleg et al. used GIS to simulate ambulance access to trauma care in two regions of Israel. They found that, in these two regions, 34\% and $62 \%$ of calls could be responded to within 8 minutes [21]. A similar approach could not be used in our study because of limited information; however, visualization of the sites where RTIs occur can aid in determining the allocation of EMS dispatch centers or trauma centers.

Despite these limitations, our study was one of the first to apply GIS for RTI research in a low-income country. Our results indicate that pre-hospital care should be implemented to reduce the effects of road traffic incidents in Hanoi. For example, building new EMS dispatch centers along Routes 3 and 8 or establishing alternative pre-hospital transportation by commercial vehicles or private ambulance would provide easier access to trauma centers in the city. We also would like to apply GIS to improve trauma management in industrialized countries such as Japan in the future. We believe that research and infrastructure to link GIS systems with hospital, EMS, or police data are needed.

In conclusion, this study has identified the geographical distribution of road traffic injuries and accessibility to trauma care in Hanoi, Vietnam. The observations provide clues for injury prevention and safety promotion 
by a multi-disciplinary approach. In particular, we recommend developing a more efficient EMS system in Hanoi. Finally, we note that GIS may help to collect, analyze, and integrate geographical and environmental data on road traffic injuries.

\section{Acknowledgements}

This study was funded by the Ministry of Health, Welfare and Labor, Japan, as the Grant for International Health Cooperation Research (19C-5). It was one of the international research projects entitled "Research for injury prevention and clinical education improvement in developing countries," directed by Dr. Akio Kimura, the director of emergency medicine and critical care, National Center for Global Health and Medicine, Tokyo, Japan. Dr. Minoru Akiyama, the official advisor for the Ministry of Health, Vietnam, and Mr. Michimasa Takagi, the project leader in education for traffic safety in Hanoi, Vietnam cooperated in the fieldwork. The data-mining and mapping processes were performed by Mr. Vu Van Chat, of the Continental Horizon Corporation in Hanoi.

This research was presented at American College of Emergency Physician, Scientific Assembly in Boston, USA, on October 5-8, 2009.

\section{Author details}

'Kyushu University Hospital, Department of Emergency and Critical Care Center, Fukuoka, Japan. ${ }^{2}$ Kurume University Graduate School of Medicine, Kurume, Japan. ${ }^{3}$ Osaka City University, Graduate School of Literature and Human Science, Osaka, Japan. ${ }^{4}$ National Center for Global Health and Medicine, Department of emergency medicine and critical care, Tokyo, Japan. ${ }^{5}$ St. Marianna University School of Medicine, Department of Preventive Medicine, Kawasaki, Japan.

\section{Authors' contributions}

TN, YK and AK originated and designed the study. TN, AT, MH, and SH interpreted the results and commented on drafts of the articles. AT and YK carried out geographical and statistical analysis. All the authors approved the final version, and will take the responsibility for the content of the paper.

\section{Competing interests}

The authors declare that they have no competing interests.

Received: 2 February 2011 Accepted: 30 September 2011 Published: 30 September 2011

\section{References}

1. Health Statistics ID, Department Planning-Finance: Health Statistics Year Book 2005. Hanoi: Ministry of Health; 2006, 159-160, pp. 159-160.

2. Ngo AD, Rao C, Hoa NP, Adair T, Chuc NT: Mortality patterns in Vietnam, 2006: Findings from a national verbal autopsy survey. BMC Res Notes 2010, 3:78.

3. Bank AD: Arrive Alive: ASEAN Commits to Cutting Road DeathsAssociation of Southeast Asian Nations Regional Road Safety Strategy and Action Plan (2005-2010). 2005.

4. Passmore J, Tu NT, Luong MA, Chinh ND, Nam NP: Impact of mandatory motorcycle helmet wearing legislation on head injuries in Viet Nam: results of a preliminary analysis. Traffic Inj Prev 2010, 11:202-206.

5. Pervin A, Passmore J, Sidik M, McKinley T, Nguyen TH, Nguyen PN: Viet Nam's mandatory motorcycle helmet law and its impact on children. Bull World Health Organ 2009, 87:369-373.

6. Mock CN: Guidelines for Essential Trauma Care Geneva: World Health Organization; 2004.

7. Bell N, Schuurman N: GIS and injury prevention and control: history, challenges, and opportunities. Int I Environ Res Public Health 7:1002-1017.

8. Edelman LS: Using geographic information systems in injury research. J Nurs Scholarsh 2007, 39:306-311.

9. Nguyen TL, Nguyen TH, Morita S, Sakamoto J: Injury and pre-hospital trauma care in Hanoi, Vietnam. Injury 2008, 39:1026-1033.

10. Son NT, Mock C: Improvements in trauma care capabilities in Vietnam through use of the WHO-IATSIC Guidelines for Essential Trauma Care. Int J Inj Contr Saf Promot 2006, 13:125-127.
11. Son NT, Thu NH, Tu NT, Mock C: Assessment of the status of resources for essential trauma care in Hanoi and Khanh Hoa, Vietnam. Injury 2007, 38:1014-1022.

12. O'Reilly GM, Cameron PA, Tan GA, Mulligan T, Hill C: The dawn of emergency medicine in Vietnam. Emerg Med Australas 2010, 22:457-462.

13. Mock CN, Tiska M, Adu-Ampofo M, Boakye G: Improvements in prehospital trauma care in an African country with no formal emergency medical services. J Trauma 2002, 53:90-97.

14. Arreola-Risa C, Mock CN, Lojero-Wheatly L, de la Cruz O, Garcia C, CanavatiAyub F, Jurkovich GJ: Low-cost improvements in prehospital trauma care in a Latin American city. J Trauma 2000, 48:119-124.

15. Van HT, Singhasivanon $P$, Kaewkungwal J, Suriyawongpaisal $P$, Khai LH: Estimation of non-fatal road traffic injuries in Thai Nguyen, Vietnam using capture-recapture method. Southeast Asian J Trop Med Public Health 2006, 37:405-411.

16. Hong TT, Walker SM, McKenzie K: The quality of injury data from hospital records in Vietnam. HIM J 2009, 38:15-21.

17. Smith RM, Conn AK: Prehospital care - scoop and run or stay and play? Injury 2009, 40(Suppl 4):S23-26.

18. Bagaria $\vee$, Bagaria S: A geographic information system to study trauma epidemiology in India. J Trauma Manag Outcomes 2007, 1:3.

19. Ong ME, Chiam TF, Ng FS, Sultana P, Lim SH, Leong BS, Ong W, Ching Tan EC, Tham LP, Yap S, et al: Reducing ambulance response times using geospatial-time analysis of ambulance deployment. Acad Emerg Med 2010, 17:951-957.

20. Schuurman N, Cinnamon J, Crooks VA, Hameed SM: Pedestrian injury and the built environment: an environmental scan of hotspots. BMC Public Health 2009, 9:233.

21. Peleg K, Pliskin JS: A geographic information system simulation model of EMS: reducing ambulance response time. Am J Emerg Med 2004, 22:164-170.

doi:10.1186/1752-2897-5-11

Cite this article as: Nagata et al:: Trauma center accessibility for road traffic injuries in Hanoi, Vietnam. Journal of Trauma Management \& Outcomes 2011 5:11.

\section{Submit your next manuscript to BioMed Central and take full advantage of:}

- Convenient online submission

- Thorough peer review

- No space constraints or color figure charges

- Immediate publication on acceptance

- Inclusion in PubMed, CAS, Scopus and Google Scholar

- Research which is freely available for redistribution

Submit your manuscript at www.biomedcentral.com/submit
C Biomed Central 